\title{
EDUCAÇÃO EM TEMPOS DE REDEMOCRATIZAÇÃO: PLANEJAMENTO E EDUCAÇÃO EM SANTA CATARINA 1985-19901
}

\author{
EDUCACIÓN EN TIEMPOS DE REDEMOCRATIDAD: PLANIFICACIÓN Y \\ EDUCACIÓN EN SANTA CATARINA 1985-1990
}

\section{EDUCATION IN REDEMOCRATIZATION TIMES: PLANNING AND EDUCATION IN SANTA CATARINA 1985-1990}

\author{
GOULARTI FILHO, Alcides \\ alcides@unesc.net \\ UNESC - Universidade do Extremo Sul Catarinense \\ https://orcid.org/0000-0002-0808-4486
}

\begin{abstract}
RABELO, Giani gra@unesc.net

UNESC - Universidade do Extremo Sul Catarinense https://orcid.org/0000-0002-3304-8268
\end{abstract}

\begin{abstract}
RESUMO O objetivo principal deste artigo é analisar e discutir os principais documentos formulados no âmbito da educação pelos governos brasileiro e catarinense na chamada redemocratização dos anos 1980, dentro de uma perspectiva crítica da educação, que busca compreender as continuidades e descontinuidades. Intenta contribuir para a história e a historiografia da educação catarinense. Enquanto metodologia, foi utilizada a pesquisa documental. A partir da análise dos documentos, conclui-se que os efeitos positivos da redemocratização da educação iniciada em meados dos anos de 1980 estenderam-se às duas décadas seguintes. Mesmo com os retrocessos da política econômica do neoliberalismo, a educação seguiu seu caminho transformador ao longo dos anos 1990. O ambiente democrático garantiu a diversidade do debate e trouxe ganhos coletivos.
\end{abstract}

Palavras-chave: Educação. Planos de Governo. Planejamento. Santa Catarina. Redemocratização.

RESUMEN El objetivo principal de este artículo es analizar y discutir los principales documentos formulados en el campo de la educación por los gobiernos de Brasil y Santa Catarina en la llamada redemocratización de la década de 1980, dentro de una perspectiva crítica de la educación, que busca comprender las continuidades y discontinuidades. Tiene la intención de contribuir a la historia y la historiografía de la educación de Santa Catarina. Como metodología, se utilizó la investigación

${ }^{1}$ Este artigo traz uma das reflexões realizadas a partir de Projeto aprovado no edital MCTI/CNPQ Universal 14/2014, intitulado DESENVOLVIMENTO, EDUCAÇÂO E PLANEJAMENTO EM SANTA CATARINA 1955-2010. 


\section{Atos de Pesquisa em Educação - ISSN 1809-0354 \\ Blumenau, v.14, n.2, supl.1, p.718-744, out./nov. 2019 \\ DOI: http://dx.doi.org/10.7867/1809-0354.2019v14n2s1p718-744}

documental. A partir del análisis de los documentos, se puede concluir que los efectos positivos de la redemocratización de la educación que comenzó a mediados de la década de 1980 se extendió a las siguientes dos décadas. Incluso con los reveses de la política económica del neoliberalismo, la educación siguió su camino transformador durante la década de 1990. El ambiente democrático aseguró la diversidad del debate y trajo ganancias colectivas.

Palabras clave: Educación. Planes de gobierno. Planificación Santa Catarina. Redemocratización.

ABSTRACT The main objective of this article is to analyze and discuss the documents formulated in the scope of education by the Brazilian and Santa Catarina governments in the so-called redemocratization of the 1980s, within a critical perspective of education that seeks to understand the continuities and discontinuities. It attempts to contribute to the history and historiography of Santa Catarina's education. Documentary research was used as methodology. From the analysis of the documents, it is concluded that the positive effects of the re-democratization of education, begun in the mid-1980s, extended to the following two decades. Even with the setbacks of neoliberal economic policy, education continued its transformative path through the 1990s. The democratic environment guaranteed the diversity of the debate and brought collective gains.

Keywords: Education. Government Plans. Planning. Santa Catarina. Redemocratization.

\section{INTRODUÇÃO}

O interesse em pesquisar essa temática ocorreu no âmbito do projeto de pesquisa denominado Desenvolvimento, Educação e Planejamento em Santa Catarina (1955-2010), que teve como objetivo central analisar a trajetória e a relação entre os planos nacionais e estaduais de educação com os planos nacionais e estaduais de desenvolvimento, bem como suas orientações para a formulação das políticas públicas educacionais em Santa Catarina.

Como objetivos específicos, foram traçados os seguintes: analisar em cada plano de desenvolvimento a participação da educação e sua concepção descrita no plano; estudar os planos estaduais de educação em sua relação com as tendências educacionais preponderantes no país; realizar um levantamento da trajetória dos gastos (custeio e capital) do governo estadual na área da educação, observando o que estava previsto em cada plano; e, por último, realizar um levantamento estatístico apontando a evolução dos principais indicadores socioeducacionais. 


\section{Atos de Pesquisa em Educação - ISSN 1809-0354 \\ Blumenau, v.14, n.2, supl.1, p.718-744, out./nov. 2019 \\ DOI: http://dx.doi.org/10.7867/1809-0354.2019v14n2s1p718-744}

Enquanto metodologia, foi utilizada a pesquisa documental baseada em amplo corpus empírico, como relatórios oficiais e de instituições, artigos de revistas especializadas, dissertações, leis, decretos e anuários.

Entre as várias análises e reflexões realizadas no decorrer de 1955 a 2010, sobre a relação entre os planos nacionais e estaduais de educação com os planos nacionais e estaduais de desenvolvimento, além de suas orientações para a formulação das políticas públicas educacionais em Santa Catarina, este artigo possui um recorte que tem o intuito de analisar e discutir os principais documentos formulados pelos governos brasileiro e catarinense no âmbito da chamada redemocratização dos anos 1980.

Concentrados, sobretudo, na redemocratização da educação em Santa Catarina, os documentos analisados são: III Plano Estadual de Educação (19851988), Plano de Ação da Secretaria de Estado de Educação (1988-1991) e Proposta Curricular (1991). Também são analisados os planos de governo estadual: Carta aos Catarinenses (1983-1986) e Santa Catarina Rumo à Nova Sociedade (1987-1990) e alguns planos nacionais com o intuito apenas de contextualizar os rumos do debate da Redemocratização da educação em nível nacional.

$\mathrm{Na}$ análise desses documentos, dentro de uma perspectiva crítica da história da educação, não interessa somente problematizar as relações do passado com o presente, mas compreender, de forma minuciosa, o que constitui o passado de nossa educação, a fim de compreender suas especificidades, bem como suas reverberações na atual política pública educacional. No entanto, fazemos essa leitura do passado a partir do presente, com o entendimento de que o passado não compreende uma história única, com o mesmo significado, e sim algo passível de múltiplas interpretações.

\section{CONTINUIDADES E DESCONTINUIDADES NA REPÚBLICA}

A história da República brasileira é marcada por continuidades e descontinuidades, momentos de avanço, recuo e recomposição. Acontecimentos que achávamos que estariam relegados apenas às páginas dos livros de história, em determinados momentos ressurgem com novas configurações. Dentro da tradição 


\section{Atos de Pesquisa em Educação - ISSN 1809-0354 \\ Blumenau, v.14, n.2, supl.1, p.718-744, out./nov. 2019 \\ DOI: http://dx.doi.org/10.7867/1809-0354.2019v14n2s1p718-744}

conservadora da política brasileira, os momentos de distensões foram respaldados pelos pactos entre as elites que fizeram valer a máxima sintetizada na célebre frase do escritor italiano Giuseppe Tomasi di Lampedusa (2007), em sua obra O Leopardo: "Para que as coisas permaneçam iguais, é preciso que tudo mude".

Em uma rápida mirada na trajetória da República brasileira, percebe-se que algumas datas assumem o caráter de divisor de águas e marcam o início de um novo rearranjo entre as elites. Os anos de 1930, 1945, 1964 e 1985 são ilustrativos e demarcam o momento da descontinuidade, porém levam consigo a continuidade do pacto conservador. Não houve ruptura, apenas choque entre gerações, com a recomposição de forças arcaicas e abertura de espaços para os novos sujeitos da história que emergem com discursos modernos.

No embalo desses discursos modernos, as forças progressistas se unem para se tornarem hegemônicas e tentam imprimir seu ritmo de modernização nas diversas esferas da sociedade. Intelectuais, artistas, estudantes e religiosos se unem aos trabalhadores, empresários e militares para construir, junto com os três poderes constituídos da República, novos contratos sociais que possibilitem a unidade nacional em torno de um projeto de país mais homogêneo.

Situações como essas ocorreram no Brasil em três grandes momentos: pós1930, 1946 e 1985. Todos foram antecedidos de momentos característicos: infâmia (pré-1930), exceções (pré-1946) e autoritarismo (pré-1985). A velha classe dominante metamorfoseia-se e assume o papel de paladina das mudanças, trazendo consigo os ranços do passado, combinando-os com a nova classe dirigente, portadora dos ares da modernidade. (FERNANDES, 1981).

A Revolução de 1930 desalojou a velha oligarquia cafeicultora paulista, de caráter liberal e agrária, do Palácio do Catete e inaugurou uma nova concepção de organização do Estado, da economia e da sociedade. Getúlio Vargas foi o grande artífice dessa Era, que nascia sob o auspício do positivismo reformista: industrialização e reformas sociais. Nas diversas esferas da existência (econômica, política e social) e nos aparelhos privados de hegemonia, a "ordem do dia" era a centralização das tomadas de decisão e o fortalecimento do Estado-Nação. O Brasil, que na concepção de Vargas se constituía como um "arquipélago de interesses", 
deveria assumir a grandeza de uma nação industrializada e forjar a construção de uma sociedade civil mais coesa e com instituições mais sólidas.

Para tanto, um novo projeto de Estado racional e burocrático deveria ser implementado para assumir a condição de demiurgo da modernização. Acomodar interesses entre as oligarquias e avançar a Nação brasileira rumo à industrialização com reformas sociais era a grande missão de Vargas, que regia uma orquestra que constantemente insistia em desafinar!

Antes de 1930, vários movimentos sociais e militares, que fervilharam no seio da sociedade brasileira, assumiram a condição de gestores do novo projeto de nação que emergia após a chegada de Vargas ao Catete. Se no passado recente esses movimentos eram apenas "panfletos lançados ao vento", agora o desafio estava posto para fazer valer suas ideias. Aos engenheiros das ferrovias, das estradas e da marinha mercante foi dada a tarefa de formular o plano nacional de viação; os empresários ligados às atividades industriais foram convidados a pensar as bases do projeto de industrialização; os médicos e sanitaristas foram incumbidos de esboçar a política nacional de saúde; e na educação, os escolanovistas assumiram a tarefa de reformar o sistema educacional brasileiro.

$\mathrm{Na}$ esteira das mudanças preconizadas pós-1930, com base no Decreto oㅡ 19.402, de 14 de novembro de 1930, foi criado o Ministério dos Negócios da Educação e Saúde Pública, tendo como ministro o educador reformista Francisco Campos. No ano seguinte, por meio do Decreto ํㅜ 19.850, de 11 de abril, foi criado o Conselho Nacional de Educação. No embalo das mudanças institucionais na educação, em 1932 foi lançado o famoso "Manifesto dos Pioneiros da Educação Nova"2.

O Manifesto definia que a educação era o principal "problema nacional" e se quiséssemos desenvolver a forças econômicas e produtivas do país necessariamente teríamos que colocar e educação como a "primazia nos planos de reconstrução nacional". Defensores da escola pública, gratuita e laica e da coeducação, os

\footnotetext{
${ }^{2}$ De acordo com Vidal (2013, p. 579), "com o subtítulo A reconstrução educacional no Brasil: ao povo $e$ ao governo, o documento foi publicado simultaneamente em vários órgãos da grande imprensa brasileira no dia 19 de março de 1932. Destaco apenas o jornal O Estado de S. Paulo, particularmente porque Júlio de Mesquita Filho, proprietário da agência, também foi signatário. A ação pretendia alcançar a maior difusão possível no território nacional. Cecília Meireles, por exemplo, fez com que o documento fosse publicado no Diário de Notícias, no Rio de Janeiro.
} 
signatários $^{3}$ do Manifesto defendiam a universalização de uma nova escola democrática em oposição ao velho modelo de escola que ainda estava fundado em alguns princípios basilares do Ratio Studiorum. Um de seus propósitos era a defesa da:

\begin{abstract}
Escola única, constituída sobre a base do trabalho produtivo, tido como fundamento das relações sociais, e pela defesa do Estado como responsável pela disseminação da escola brasileira. Nesse sentido, distinguia-se do que denominava educação tradicional, particularmente no que considerava como a maior contribuição da Escola Nova: a organização científica da escola. (VIDAL, 2013, p. 279).
\end{abstract}

Entre as várias bandeiras dos escolanovistas, constava a defesa de um "plano geral de educação" para que o Estado garantisse a cada indivíduo sua educação integral, compreendida como um direito biológico. Tal plano deveria ter uma estrutura orgânica capaz de tornar a educação efetiva em todos os seus graus e acessível aos cidadãos "em condições de inferioridade econômica para obter o máximo de desenvolvimento de acordo com as suas aptidões vitais". (AZEVEDO et al., 2010, p. 44). Esta defesa fundamentava o princípio da "escola comum ou única" para todos. Ou seja, a educação não poderia ser, para os escolanovistas, um privilégio econômico.

Entre os preceitos contidos na nova Carta Magna aprovada em 16 de julho de 1934, estava prevista a elaboração de um "plano nacional de educação", que deveria abranger todos os graus e ramos do ensino do país. No dia 17 de maio de 1937, o Conselho Nacional de Educação apresentou o Plano Nacional de Educação, que deveria ser debatido e votado pelo Congresso Nacional. No entanto, em função da implantação do Estado Novo em 10 de novembro de 1937, o projeto foi abortado. De toda forma, muitos de seus princípios foram executados por Capanema, que se manteve no comando do Ministério de Educação e Saúde Pública de julho de 1934 até outubro de 1945. Em relação a este processo:

Em maio de 1937, o Conselho Nacional de Educação encaminha a Capanema o texto final do plano, que é enviado pelo presidente da República ao Congresso para aprovação. Em seu art. 1ํ estava previsto que o plano só poderia ser alterado após 10 anos de vigência, e Capanema solicita sua

${ }^{3} \mathrm{O}$ texto foi assinado por 26 intelectuais, entre os quais Anísio Teixeira, Afrânio Peixoto, Lourenço Filho, Roquette Pinto, Delgado de Carvalho, Hermes Lima e Cecília Meireles. 
Atos de Pesquisa em Educação - ISSN 1809-0354

Blumenau, v.14, n.2, supl.1, p.718-744, out./nov. 2019

DOI: http://dx.doi.org/10.7867/1809-0354.2019v14n2s1p718-744

aprovação "em globo". Era um documento extenso, com 504 artigos ao longo de quase 100 páginas de texto, e buscava consagrar uma série de princípios e opções educacionais, de forma alguma consensuais, e cuja discussão a proposta de "aprovação em globo" visava, justamente, a evitar. (BOMENY, 1999, p. 137).

Após a deposição de Getúlio Vargas em 29 de outubro de 1945, abriu-se um período de redemocratização das instituições e de abertura política. A descontinuidade histórica se deu com o alijamento das forças populares e trabalhistas, mas a continuidade seguiu adiante com a retomada do Palácio do Catete pelas oligarquias retrógradas de São Paulo e Minas Gerais. O projeto nacional de desenvolvimento foi colocado em xeque, mas não sofreu grande revés, afinal as forças produtivas avançavam e se colocavam acima dos interesses da velha oligarquia. Com relação à educação, a Constituição de 18 de setembro de 1946, no Artigo 5, definiu que a União legislaria sobre as "diretrizes e bases da educação nacional".

Cumprindo os preceitos constitucionais e no embalo da redemocratização, no dia 29 de outubro de 1948, o Ministro Clemente Mariani Bittencourt apresentou ao Congresso Nacional o segundo projeto de lei que fixava as diretrizes e bases da educação nacional. Como é de conhecimento, esse projeto tramitou no Congresso durante 13 anos até ser aprovado por meio da Lei № 4.024, de 20 de dezembro de 1961 - a primeira Lei de Diretrizes e Bases da Educação (LDB) -, durante o governo de João Goulart.

Nesse ínterim, o lema "educação para o desenvolvimento" fez parte dos planos nacionais de desenvolvimento e a educação passou a ser vista como um instrumento para a rápida industrialização do país. $O$ fortalecimento das forças populares se adensava no setor educacional e ganhava cada vez mais espaço nas instituições de ensino e pesquisa do país, fazendo-se valer "na prática" dos pilares da Escola Nova.

A euforia da LDB e a crescente universalização da educação culminou com o programa de Reforma de Base, que visava avançar com as reformas sociais. No entanto, estas foram sufocadas com o golpe militar de 31 de março de 1964. As trevas que assolaram a sociedade brasileira penetraram em todos os poros com o único objetivo de estripar as conquistas alcançadas após a redemocratização de 1946. A LDB foi esfacelada por meio de um decreto e duas leis que reformularam o sistema educacional brasileiro. A Lei ํㅜ 5.540, de 28 de novembro de 1968, e o Decreto-Lei no 


\section{Atos de Pesquisa em Educação - ISSN 1809-0354 \\ Blumenau, v.14, n.2, supl.1, p.718-744, out./nov. 2019 \\ DOI: http://dx.doi.org/10.7867/1809-0354.2019v14n2s1p718-744}

464, de 11 de fevereiro de 1969, reformularam o ensino universitário brasileiro, e a Lei ํo 5.692, de 11 de agosto de 1971, o ensino de $1^{\circ}$ e $2^{\circ}$ graus.

Esse conjunto de reformas conservadoras no sistema educacional brasileiro sepultou temporariamente as lutas populares que estavam ocorrendo desde os debates no campo progressista. Nascia o tecnicismo e a "moral e cívica" na educação brasileira. A educação pública, que vinha crescendo, ampliando sua área de abrangência e sobrepondo-se ao ensino privado, sofreu um revés com a "privatização da educação". Abriu-se mais espaços para que grupos econômicos privados também pudessem "investir" na educação, ofertando ensino nos três níveis de formação.

Se pós-1930 e 1946 tivemos momentos de continuidade, com a ampliação do conceito de educação pública e gratuita e com a participação de intelectuais progressistas no comando, o pós-1964 foi uma descontinuidade, com a tentativa de anular os ganhos acumulados e impor reformas autoritárias e conservadoras. A vitória dos conservadores durou 20 anos, mas as vozes dos desterrados insistiam em semear a esperança nesse campo fértil que é a educação.

\section{ABERTURA E DISTENSÃO NA DITADURA}

A ditadura chega ao final dos anos 1970 apresentando fissura e desgastes. A abertura "lenta, gradual e segura" iniciada pelo General Ernesto Geisel necessariamente deveria ser substituída pela abertura "ampla, geral e irrestrita" do General João Batista Figueiredo. No final da década, uma explosão de acontecimentos políticos somou-se à desaceleração da economia brasileira e desaguou no movimento pela redemocratização da educação e da sociedade. A greve dos metalúrgicos no $A B C$ anunciava que não era mais possível tolerar por muito tempo o "arrocho salarial" e a opressão operária por meio da repressão e prisão de líderes sindicais. Pelo lado estudantil, após 13 anos de clandestinidade, a União Nacional dos Estudantes (UNE) ressurge em maio de 1979 no $31^{\circ}$ Congresso, em Salvador. As distensões se alastravam em toda a sociedade, levando ao esgotamento da ditadura.

A promessa do General Figueiredo de que "nem mil bombas" Ihe impediriam de "fazer deste país uma democracia", ao pouco ia se concretizando com a promulgação da Lei oㅡ 6.683, de 28 de agosto de 1979 - a Lei da Anistia -, a volta dos exilados, o surgimento dos novos partidos políticos e a promessa de eleições para 


\section{Atos de Pesquisa em Educação - ISSN 1809-0354 \\ Blumenau, v.14, n.2, supl.1, p.718-744, out./nov. 2019 \\ DOI: http://dx.doi.org/10.7867/1809-0354.2019v14n2s1p718-744}

governadores. No campo da educação, a volta de grandes intelectuais do exílio militantes como Darcy Ribeiro, Paulo Freire e Florestan Fernandes - reacendeu a esperança de ser retomado o debate interrompido em defesa da educação universal, pública, gratuita e emancipadora.

Os sinais da redemocratização da educação brasileira também começaram a surgir nos documentos oficiais do executivo federal que traçavam as metas e diretrizes gerais das ações governamentais. Dentro do III Plano Nacional de Desenvolvimento (1980-1985), apresentado como continuidade dos planos anteriores, houve o abandono do discurso da educação voltada para a produtividade. Além disso, percebe-se a adesão aos novos tempos de redemocratização, uma vez que se definiu a educação como direito fundamental para a construção das liberdades e da cidadania. A educação passa a ser tratada como um instrumento fundamental para a distribuição de renda, a participação política e a obtenção de uma sociedade mais democrática. As ações prioritárias seriam a educação no meio rural e nas periferias urbanas. (BRASIL, 1980).

Outro documento norteador das ações do executivo era o Plano Setorial de Educação, Cultura e Desporto, elaborado pelo Ministério da Educação e Cultura. O primeiro plano foi para o triênio 1972-1974; o segundo, para o qüinqüênio 1975-1979; e o terceiro, para o sexênio 1980-1985. No último plano, imbuído dos ares da abertura política, a educação foi definida como um instrumento para a redução das desigualdades sociais e fomentadora da participação política para que se "obtenha uma sociedade democrática". (BRASIL, 1982, p. 16). A educação e a cultura seriam os espaços adequados para se conquistar a liberdade e a cidadania. Conclusões dessa natureza possibilitavam que os militantes de uma educação libertadora se apoiassem também nos documentos oficiais para justificar e sustentar suas bandeiras de lutas. Eram pequenas brechas que abriam novos campos de debate.

Santa Catarina sentiu todos os tensos desdobramentos da distensão da ditadura e as pressões para a abertura política. Um dos episódios mais emblemáticos dos primeiros anos do governo Figueiredo foi a Novembrada ${ }^{4}$, uma manifestação

\footnotetext{
${ }^{4}$ De acordo com Fáveri (2014, p. 61), "o acontecimento conhecido como Novembrada ocorreu no dia 30 de novembro de 1979, em Florianópolis. Estudantes organizaram um ato de protesto por ocasião da vinda do então presidente João Batista Figueiredo. Ao ato dos estudantes que se manifestavam contra o regime ditatorial juntaram-se populares que acompanhavam a solenidade na praça XV de Novembro, com palavras de ordem contra a carestia, o arrocho salarial e expressando a ineficiência do
} 
popular que ocorreu no dia 30 de novembro, na cidade de Florianópolis, em protesto contra a visita do Presidente ao estado. Marcada pela participação dos acadêmicos do Diretório Central dos Estudantes da Universidade Federal de Santa Catarina, o episódio inflou ainda mais os ânimos dos movimentos que clamavam por mais democracia.

E a exemplo de outros estados e capitais brasileiras, em Santa Catarina o movimento pela anistia também foi significativo, com intensa participação de expresos políticos, militantes de esquerda e democratas. Nesse campo que estava sendo fertilizado, brotavam diversos movimentos que exigiam mais participação política, fosse nas igrejas, nos sindicatos ou nas escolas. Sendo a escola um espaço privilegiado para o debate político, ela se transformou na caixa de ressonância do movimento de redemocratização. Afinal, os documentos oficiais a elegiam como "fomentadora da participação política".

\section{O PREÂMBULO DA REDEMOCRATIZAÇÃO EM SANTA CATARINA}

A abertura política e a anistia abriram espaço para a criação dos partidos políticos no Brasil, que foi regulamentada pela Lei oㅜ 6.767 de 20 de dezembro de 1979. Após esses primeiros passos na redemocratização, em 1982 foram realizadas eleições para governadores. Os candidatos do Partido Democrático Social (PDS), Esperidião Amin e Victor Fontana, foram eleitos para os cargos de governador e vicegovernador, respectivamente. Esperidião Amin, mesmo representando os interesses dos generais de Brasília, apresentou um plano de governo intitulado Carta aos Catarinenses, que se propunha a transformar o Estado na condição de "súdito do homem e não seu soberano". (AMIN; FONTANA, 1982, p. 2).

Fundada na "prioridade aos pequenos", a Carta aos Catarinenses refletia alguns anseios de reversão da lógica do Estado, que não poderia se voltar mais para a "distribuição e menos ao crescimento". Para concretizar as ações destinadas à "distribuição" o Estado deveria voltar-se "preferencialmente àqueles segmentos sociais que dispõem de menores recursos". (AMIN; FONTANA, 1982, p. 2). Mesmo

governo militar em resolver a crise econômica. O evento foi marcado pela truculência do presidente da República no trato com os estudantes, prisões e enquadramentos na Lei de Segurança Nacional; o movimento ganhou a rua por vários dias em protesto contra estas prisões". 
assumindo um caráter conservador, a Carta aos Catarinenses estava fundada em princípios mais progressistas, valorizando a "solidariedade". Porém, há uma discrepância entre um documento progressista e sua implementação, haja vista que a equipe de governo era composta por membros ligados à ditadura.

Esperidião Amin assume o cargo de governador em 15 de março de 1983 (até 15 de março de 1987) e, logo em seguida, no mês de maio, enfrenta uma greve dos professores da rede estadual de ensino. Na pauta de reivindicações dos grevistas também estava presente a necessidade de elaborar um novo Plano Estadual de Educação (PEE) com a ampla participação dos professores e profissionais de educação. Assim que os professores retomaram suas atividades, o governo estadual criou uma comissão, presidida pelo reitor da Universidade do Estado de Santa Catarina (Udesc), Lauro Ribas Zimmer, cuja missão seria coordenar e elaborar o novo Plano. (SANTA CATARINA, 1985).

O primeiro Plano Estadual de Educação aprovado em Santa Catarina foi o de 1969, com prazo previsto de execução para dez anos. O PEE estava fundamentado em princípios cristãos e católicos, além de fazer uma análise behaviorista do processo de ensino e aprendizagem. Para solucionar a evasão e a repetência foi proposto 0 sistema de Avanço Progressivo, no qual o aluno faria uma recuperação apenas na $4^{\underline{a}}$ série do Primário e na $8^{\underline{a}}$ série do Ginásio. O Plano foi aprovado pela Assembleia Legislativa, por meio da Lei Estadual no 4.394, de 20 de novembro de 1969. (SANTOS, 1970). Esse plano basicamente não foi alterado ao longo da década de 1970, sendo fortalecido com a Lei de Diretrizes e Bases da Educação Nacional no 5.692/1971, de cunho tecnicista.

Após cumprir seu prazo de execução, em 1980, foi apresentado o segundo PEE, para um prazo previsto de quatro anos. O sistema de Avanço Progressivo não foi revisto, pelo contrário, foi elogiado e reforçado. Logo no início do texto, na parte introdutória do referido plano, afirma-se que:

Dentre as medidas preconizadas pelo Plano Estadual de Educação 1969-80, a implantação do sistema de avanços progressivos, no ensino de 1ํㅡrau, se constitui numa proposta inovadora e avançada que o presente plano retoma e reforça, a partir das revisões realizadas em torno de sua operacionalização. Evitando-se confundi-lo com aprovação automática e criando as condições para a sua efetiva realização, o avanço progressivo é considerado no presente Plano, como uma atitude pedagógica que leva em conta o ajustamento do ensino à capacidade do aluno e ao seu ritmo individual 


\section{Atos de Pesquisa em Educação - ISSN 1809-0354 \\ Blumenau, v.14, n.2, supl.1, p.718-744, out./nov. 2019 \\ DOI: http://dx.doi.org/10.7867/1809-0354.2019v14n2s1p718-744}

de aprendizagem, o que se constitui, obviamente, num princípio básico da educação. (PPE, 1980-1983, p, 1, grifo nosso).

Novamente imperava uma visão tecnicista da educação, que visava aproximála cada vez mais do mercado de trabalho e das demandas do setor produtivo, visto que o viés pedagógico pautava-se no princípio de que deveria se buscar o "ajustamento do ensino à capacidade do aluno e ao seu rítimo individual de aprendizagem", levando ao entendimento de que bastaria formar um indivíduo produtivo, ou seja, uma mão de obra. Com destaque, o Plano também discutia a necessidade de valorizar a carreira do magistério. (SANTA CATARINA, 1980).

Para elaboração do novo Plano no governo Amin (1983 a 1987), com base na participação popular, foi definida uma metodologia de trabalho organizada em seminários e congressos municipais e regionais com forte esforço para que toda a comunidade escolar participasse das reuniões. Calcula-se que aproximadamente 1,5 milhões de pessoas participaram direta ou indiretamente dos debates. Em seguida, após compilar todas as contribuições e reivindicações dos debates realizados na esfera local, entre os dias 22 e 27 de outubro de 1984 realizou-se, na cidade de Lages, - Congresso Estadual, formado por 538 delegados eleitos nas 20 regiões educacionais. Nesse Congresso foi eleita a comissão responsável pela redação do novo Plano.

O terceiro Plano Estadual de Educação foi aprovado pelo Conselho Estadual de Educação por meio da Resolução № 02/85, do dia 12 de março de 1985, para o período de 1985-1988:

Art. 10 Acolher o documento-processo "Democratização da educação: a opção dos catarinenses" como instrumento alimentador das ações de governo no campo educacional, previsto na Carta dos Catarinenses, e resultado do princípio democrático-representativo que a orienta. (SANTA CATARINA, 1985, p. 5).

Mesmo não estando presente como meta a ser realizada na Carta dos Catarinenses, apresentada em 1982, o Conselho Estadual de Educação creditou ao governo o PEE como se fosse uma promessa de campanha de Esperidião Amin. De acordo com o $3^{\circ} \mathrm{PEE}$, os principais problemas existentes na educação catarinense eram os seguintes: 
Atos de Pesquisa em Educação - ISSN 1809-0354

Blumenau, v.14, n.2, supl.1, p.718-744, out./nov. 2019

DOI: http://dx.doi.org/10.7867/1809-0354.2019v14n2s1p718-744

- Generalizada insatisfação com a atual situação do sistema de ensino de Santa Catarina, ficando claro o desejo de mudança;

- Necessidade de participação dos agentes do ensino na elaboração do Plano;

- Necessidade de ampliação de maior volume de recursos financeiros do poder público na educação;

- $\quad$ Necessidade de descentralizar a administração educacional;

- Necessidade de melhorar a qualidade do ensino, em todos os níveis e redes;

- Necessidade de democratizar a educação. (SANTA CATARINA, 1985, p. 15).

Imbuídos do espírito da época, a democratização e a participação se transformaram nos eixos centrais do Plano. A escola era vista como instrumento para o processo de democratização. Entendia-se a democratização como algo mais amplo, não apenas restrita ao ambiente escolar:

É impossível pensar em democratizar a educação sem democratizar também toda a sociedade brasileira. Isto significa defender a soberania nacional e reformular a política socioeconômica, promover a descentralização econômico-administrativa e a reforma tributária, com vistas a proporcionar a todos melhores condições de vida. (SANTA CATARINA, 1985, p. 20).

Na verdade, o Plano extrapolava sua esfera de atuação no campo da educação e entrava em grandes problemas nacionais, como defender o direito de eleger 0 Presidente da República, promover a redistribuição de renda e ampliar a participação popular em todas as esferas do poder. Após 20 anos de ditadura e cerceamento de direitos políticos, quando se abria a possibilidade de participação política na esfera do poder público, os trabalhadores organizados, os movimentos sociais e a oposição político-partidária aproveitavam a oportunidade para expor suas pautas de reivindicações fundadas na redemocratização e na participação popular. Em algumas passagens do Plano, há críticas à chamada "ideologia dominante", que remetia à ditadura militar, a intervenção da "politicagem" e o abuso do poder político na educação.

Uma das grandes mudanças implementadas pelo novo PEE foi o fim do Avanço Progressivo, portanto foram extintas as classes da $4^{\underline{a}}$ e $8^{\underline{a}}$ série de recuperação. A partir desse momento, todos os alunos estavam sujeitos a reprovação caso não alcançassem os objetivos definidos no plano de ensino da escola e do professor. 
A exemplo dos outros dois Planos e ainda com base na Lei ํㅜ 5.692/1971, a estrutura do ensino estava organizada em: educação pré-escolar, ensino de $1^{\circ}$ e $2^{\circ}$ graus, ensino superior, ensino supletivo e educação especial. Também foram incluídas no Plano metas para a assistência do educando (alimentação, ajuda financeira, saúde, segurança, esporte, lazer e auxílio profissional). Pela primeira vez foi incluída a "ecologia" como tema relevante para ser debatido em sala de aula e para converter-se em política de Estado.

Com relação à administração do sistema, a crítica central estava na "influência político-partidária". Defendiam-se a descentralização das tomadas de decisão e a desburocratização dos processos administrativos e da escolha dos dirigentes escolares. Por fim, como proposta para a categoria dos professores, o Plano previa a elaboração de um novo Estatuto e um Plano de Carreira do Magistério.

O PEE expressou o desejo pela redemocratização e incorporou os ares da mudança que estava em curso na sociedade e na política brasileira. Porém, ter em mãos um documento democrático e progressista em nada garantia sua execução. $\mathrm{Na}$ definição do novo pacto entre as elites liberais e conservadoras que estava em marcha, havia espaço para a formulação de documentos reivindicatórios de cunho progressista. No entanto, a implantação de suas propostas necessariamente passaria pela disputa orçamentária, significando que setores conservadores teriam de abrir mãos de recursos. E o mais grave, a radicalização da democracia também não interessava aos conservadores e liberais. As coisas estavam mudando para continuar as mesmas.

\section{UM PASSO À FRENTE E RECUO À VISTA}

A frustração do movimento pelas "Diretas Já" não impediu que forças populares seguissem adiante na luta por mais democracia e mais participação. A posse de José Sarney em 15 de março de 1985 era a síntese do novo pacto entre as elites: mantinha os resquícios do "entulho autoritário" e incorporava os liberais democratas. A promessa de uma nova Constituição mantinha acesa a chama de que a mudança era possível e a construção de um país mais justo e soberano seria alcançada com uma carta constitucional. 
Em âmbito nacional, foi apresentado o I Plano Nacional de Desenvolvimento da Nova República (I PND-NR), aprovado por meio da Lei no 7.486, de 06 de junho de 1986, para o período 1986-1989. Segundo as diretrizes do I PND-NR, este estava pautado em três metas estratégicas: reformas, crescimento econômico e combate à pobreza. Expressando o clima de euforia após o anúncio do plano de estabilização da inflação, em fevereiro de 1986 - Plano Cruzado -, o I PND-NR ainda guardava fortes traços do ideário nacional-desenvolvimentista. As reformas do Estado seriam no sentido de fortalecê-lo para retomar sua condição de coordenador e orientador do crescimento econômico e da distribuição da renda.

Com relação às metas destinadas à educação, o I PND-NR preconizava o seguinte:

\footnotetext{
Universalizar o ensino de $1^{\circ} \mathrm{grau}$; melhorar e ampliar o $2^{\circ} \mathrm{grau}$; redimensionar as modalidades supletiva e especial de ensino; estabelecer padrões mais elevados de desempenho acadêmico; integrar a educação física e o desporto no processo educacional; utilizar recursos tecnológicos para fins educativos e, finalmente, redefinir as competências institucionais no exercício dos encargos públicos constituem objetivos básicos das ações que integram as linhas programáticas da educação. (BRASIL, 1986, p. 65).
}

O Plano também criticava o excesso de centralização dos recursos públicos destinados à educação, a rigidez dos processos decisórios concentrados e a sobreposição das competências entre os diversos órgãos governamentais. Percebese que era uma crítica à "burocratização dos processos educativos", uma herança do período autoritário, que associava a necessidade da centralização das tomadas de decisão com a "segurança nacional".

Colhendo os bons resultados econômicos do Plano Cruzado, o Partido do Movimento Democrático Brasileiro (PMDB) elegeu a ampla maioria do Congresso Nacional e quase a totalidade dos governadores de Estado. Em Santa Catarina, o PMDB elegeu a dupla Pedro Ivo Campos e Casildo Maldaner (1987-1990).

No lançamento da candidatura de Pedro Ivo e Maldaner, foi apresentado o plano de governo intitulado "Rumo à Nova Sociedade Catarinense", composto por quatro cadernos que abrangiam as diversas áreas da sociedade e da economia. $O$ plano era resultado de 17 seminários realizados pelo PMDB em diversas cidades catarinenses que, ao todo, reuniram 6 mil pessoas, incluindo 600 lideranças comunitárias. 
Fundado no princípio de que a educação deveria se adaptar às novas realidades para permitir que o ser humano tenha bem-estar e "pleno desenvolvimento das suas potencialidades" (CAMPOS; MALDANER, 1986, p. 9), as principais diretrizes para a educação eram as seguintes:

a) Repensar o sistema educacional: elaborar uma nova estrutura curricular que inclua trabalho vocacionado, atividades artísticas e desportivas.

b) Melhorar o desempenho: valorizar a carreira dos professores e profissionais da educação.

c) Municipalizar o ensino: repassar de forma seletiva e gradual aos municípios o ensino pré-escolar e do $1^{\circ}$ grau.

d) Garantir acesso e permanência: criar condições para permitir o acesso e a permanência à população em idade escolar, além de garantir a recuperação dos repetentes e a rematrícula dos que abandonaram a escola. e) Profissionalizar de verdade: ampliar e modernizar o ensino profissionalizante do $2^{\circ}$ grau e criar novas habilidades técnicas conforme as demandas regionais.

f) Controlar a qualidade: criar mecanismos de avaliação permanente do desempenho das atividades educativas.

g) Integrar e fortalecer o $3^{ }$grau: integrar o sistema da Associação Catarinense das Fundações Educacionais (ACAFE), incentivar o ensino, a pesquisa e a extensão universitária.

h) Reordenar a administração: implementar novo processo administrativo com o intuito de descentralizar e desburocratizar as tomadas de decisões com o objetivo de torná-las mais eficientes.

Com base nas metas estabelecidas no plano "Rumo à Nova Sociedade Catarinense", a nova equipe da Secretaria de Estado da Educação elaborou o "Plano de Ação" para o período 1988-1991. Inicialmente, esse documento seria apresentado como um novo Plano Estadual de Educação, porém não chegou a ser analisado pelo Conselho Estadual de Educação, nem se converteu em lei estadual aprovada na Assembleia Legislativa.

Dentro dos pressupostos do Plano de Ação, a democratização da educação era vista como o "acesso de todos os cidadãos ao saber universal sistematizado" que envolvia a "participação, a superação da postura burocrática nos procedimentos e na estruturação organizacional e na descentralização das decisões". (SANTA CATARINA, 1988, p. 7). A participação era a condição necessária para serem construídos com toda a sociedade "os caminhos da educação", que levassem em consideração as necessidades eleitas pelo conjunto da sociedade. Era uma obrigação do Estado, por meio de instrumentos legais, financeiros, administrativos e pedagógicos, ofertar escola para todos. 
O Plano de Ação apresentava cinco grandes desafios: 1) superação das dificuldades de acesso à escola; 2) escolarização básica para todos; 3) garantia de permanência do aluno na escola; 4) reorganização curricular e 5) formação de recursos humanos e promoção da pesquisa e da extensão. Os desafios abriam-se em três programas: 1) superação das dificuldades de acesso para garantir a escolarização básica a todos; 2) garantia de permanência dos alunos na escola e 3) descentralização e modernização administrativa. Cada programa estava subdividido em diversos projetos. Dentro do segundo programa, um dos projetos previstos era a "reorganização curricular do ensino de $1^{\circ}$ e $2^{\circ}$ graus". Segundo o Plano de Ação, as metas desse projeto seriam:

- Estabelecimento de linhas norteadoras do currículo, de forma a propiciar a inter-relação entre educação e trabalho, garantindo a formação geral, científica e tecnológica;

- Definição dos conteúdos básicos essenciais de cada componente curricular, indispensáveis à escolarização do aluno, adequando-os e organizando sequencialmente;

- Reestruturação do currículo dos cursos de magistério de $1^{\circ} \mathrm{grau}, 1^{\mathrm{a}} \mathrm{a}$ 4⿳亠口了 série, visando a preparação adequada do professor. (SANTA CATARINA, 1988, p. 24).

Em âmbito nacional, o processo de redemocratização avançava com os trabalhos da constituinte, que mobilizou diversos setores organizados da sociedade que marchavam até Brasília para terem incluídas suas reivindicações na nova Carta Magna. O tema da educação entrou em vários artigos da nova Constituição, sempre reforçando seu caráter inclusivo e transformador. No artigo 214, ficou designada a elaboração de um plano nacional de educação para o período de dez anos, cujo objetivo seria:

Articular o sistema nacional de educação em regime de colaboração e definir diretrizes, objetivos, metas e estratégias de implementação para assegurar a manutenção e desenvolvimento do ensino em seus diversos níveis, etapas e modalidades por meio de ações integradas dos poderes públicos das diferentes esferas federativas. (BRASIL, 1988).

Como resultado final, a execução do plano deveria conduzir às seguintes metas:

I - erradicação do analfabetismo;

II - universalização do atendimento escolar; 


\section{Blumenau, v.14, n.2, supl.1, p.718-744, out./nov. 2019}

DOI: http://dx.doi.org/10.7867/1809-0354.2019v14n2s1p718-744

III - melhoria da qualidade do ensino;

IV - formação para o trabalho;

V - promoção humanística, científica e tecnológica do País. (BRASIL, 1988).

Ressalta-se que, no Artigo 22, das competências da União, o inciso XXIV prevê que deverá a União legislar sobre as "diretrizes e bases da educação nacional".

Em Santa Catarina, a nova Constituição, aprovada em 5 de outubro de 1989, e inspirada na federal, definiu, em seu Artigo 166, que o governo estadual deveria elaborar um "plano estadual de educação", em consonância com os planos nacional e municipais, cujos objetivos básicos seriam os mesmos apontados no Artigo 214 da Constituição Federal.

$\mathrm{Na}$ "Política Nacional de Educação", apresentada pelo Ministro da Educação Carlos Sant'Anna, em 26 de setembro de 1989, em uma palestra proferida na Escola Superior de Guerra, foi reafirmado o compromisso do Ministério em cumprir os preceitos constitucionais que determinavam a formulação do plano nacional de educação e das diretrizes e bases da educação. (BRASIL, 1989).

Esses dois importantes documentos iriam orientar a nova política educacional do Brasil pós-1990, que nascia com a redemocratização pós-1985. Porém, concomitantemente aos avanços do processo de redemocratização, as forças conservadoras, que também faziam parte do pacto das elites que assumiu o comando da política nacional no governo Sarney, estavam ensaiando um pacto formado pelos neoliberais que almejavam usurpar o patrimônio público por meio das privatizações.

\section{PROPOSTA CURRICULAR DE 1991, O "CANTO DO CISNE" DA REDEMOCRATIZAÇÃO}

Pedro Ivo Campos assumiu o governo em Santa Catarina em 15 de março de 1987 para um mandato de quatro anos, que se encerraria em 15 de março de 1991. Porém, Pedro Ivo veio a falecer em 27 de fevereiro de 1990, e seu vice, Casildo Maldaner, assumiu o cargo de governador e o cumpriu até o final. O ano de 1990 marca o início de um novo momento na economia brasileira, com a posse de Fernando Collor de Mello como presidente da República, pautado pelas políticas neoliberais de abertura comercial e econômica, privatizações e redução do papel do Estado na economia e na sociedade. 
Nesse mesmo ano, houve eleições para deputados, senadores e governadores e os neoliberais ampliaram sua participação na esfera estatal. Em Santa Catarina, foram eleitos os candidatos do Partido da Frente Liberal (PFL) Vilson Pedro Kleinubing e Antônio Carlos Konder Reis, que assumiriam os mandatos de 15 de março de 1991 até 15 de março de 1995. Sendo assim, as políticas definidas pela Secretaria de Educação em seu Plano de Ação para o quadriênio 1988-1991 tinham ainda uma "sobrevida" até essa data para cumprir suas metas. Entre elas, a elaboração da proposta curricular para a rede estadual de ensino.

Cumprindo uma das metas do Plano de Ação, em maio de 1988 realizou-se em Blumenau o Encontro de Componentes Curriculares, que abriu os trabalhos para a elaboração da nova proposta curricular. Na sequência, realizou-se, em fevereiro de 1989, o Seminário Interno da Coordenadoria de Ensino, que estruturou e sistematizou as ações da proposta. A partir da constituição de grupos de trabalhos, desencadeouse uma série de reuniões e encontros, nas principais cidades catarinenses, que se estendeu até dezembro de 1989.

Por fim, ao longo da década de 1990, os grupos de trabalho debateram e sugeriram os conteúdos a serem ministrados em sala de aula. As reuniões ocorriam por Unidades de Coordenação Regional de Educação (UCRE) distribuídas em 22 cidades catarinenses. Após compilar e sistematizar todo o debate ocorrido nos polos regionais, na sessão do dia 14 de agosto de 1991 do Conselho Estadual de Educação, foi aprovada a primeira Proposta Curricular do Estado de Santa Catarina. (SANTA CATARINA, 1991).

$\mathrm{Na}$ introdução da Proposta, o coordenador de ensino Paulo Hentz anuncia que o documento está fundado em uma "linha única":

Educação transformadora, pressupondo o resgate do conteúdo científico através da escola, conteúdo este trabalhado a partir da realidade social concreta do aluno, direcionando para o entendimento crítico do funcionamento da sociedade e interdisciplinarmente abordado na perspectiva da totalidade. (HENTZ, PS/SC, 1991, p. 3).

O "Documento norteador da proposta curricular" esboça as linhas teóricas e metodológicas que vão direcionar a Proposta. Percebe-se claramente que a abordagem marxista e gramsciana perpassa todo o documento. Conceitos como totalidade, contradições, transformação social e realidade concreta perpassam todo 0 
 \\ Blumenau, v.14, n.2, supl.1, p.718-744, out./nov. 2019 \\ DOI: http://dx.doi.org/10.7867/1809-0354.2019v14n2s1p718-744
}

texto de abertura. A justificativa para a elaboração da proposta se dava porque o ensino brasileiro (e catarinense, por extensão) ainda estava voltado

\begin{abstract}
Para uma pedagogia que não atende os anseios dos segmentos majoritários da sociedade, e sim a um processo de seletividade e excludência deste mesmo segmento, privilegiando os segmentos minoritários. Superar esta dicotomia, é democratizar em todos os níveis a educação. A não-superação deste quadro é permanecer trabalhando a educação formal como repassadora de um conjunto de "saberes" prontos e acabados, o que vem a negar a educação como processo dinâmico. (SANTA CATARINA, 1991, p. 11).
\end{abstract}

A Proposta estava dividida em ensino pré-escolar, alfabetização, ensino do $1^{\circ}$ grau (diversas disciplinas) e $2^{\circ}$ grau (disciplinas do Curso de Magistério), além de um texto que auxiliava as escolas a elaborarem o Plano Político Pedagógico Escolar. Cada grupo de trabalho foi formado por consultores e professores e funcionários vinculados à Secretaria de Educação (sendo um membro de cada região para cada disciplina). Apesar da Proposta apresentar as disciplinas de forma separada, os fundamentos que norteavam o trabalho dos diversos grupos eram os mesmos, ou seja, crítico-social e interdisciplinar.

Tendo a compreensão de que a educação é em si a totalidade do contexto no qual ela está inserida, a prática pedagógica deve buscar a superação da compartimentalização do ensino, através do trabalho a nível de suas especificidades, mas com a clareza que a compreensão da totalidade é que produz a dimensão do trabalho das partes. (SANTA CATARINA, 1991, p. 11).

As orientações para a elaboração do Plano Político Pedagógico seguem a mesma linha teórico-metodológica que orientou os textos específicos para cada disciplina:

Entendemos que o Plano Político Pedagógico Escolar deve ter como base um estudo profundo de como se concebe o mundo, a sociedade, o Homem e a educação formal como uma totalidade. Para que isto ocorra, faz-se necessário estudo, reflexões e debates conclusivos no interior das escolas para tal definição. (SANTA CATARINA, 1991, p. 85).

O Plano deveria ser elaborado por meio de debates realizados em cada unidade escolar, a partir das condições concretas em que está inserida a comunidade escolar. 


\section{Atos de Pesquisa em Educação - ISSN 1809-0354 \\ Blumenau, v.14, n.2, supl.1, p.718-744, out./nov. 2019 \\ DOI: http://dx.doi.org/10.7867/1809-0354.2019v14n2s1p718-744}

Mesmo sendo elaborada durante os anos de 1989 e 1990, período do governo de Pedro Ivo e Casildo Maldaner, a Proposta foi aprovada somente no governo de Vilson Kleinübing (14 de agosto de 1991), que tinha uma orientação partidária diferente daquela da equipe que coordenou os trabalhos. A mudança de governo não interrompeu o trabalho acumulado de quase três anos. Em Santa Catarina, o espírito da redemocratização da educação, cristalizado na Proposta Curricular, ainda teve uma sobrevida nos primeiros anos da "era neoliberal".

Quando analisamos a diferença entre a qualidade do debate e a concepção de educação nos planos de governo (nacional e estadual), planos de educação e propostas curriculares percebem-se as seguintes contradições:

- Educação nos planos de governo: elaborada por pessoas ligadas ao partido político; explicita a tensão entre a educação transformadora e a educação mercantilista/tecnicista; atende demandas imediatas e fugazes; há superficialidade e descontinuidades em relação aos debates teóricos e pedagógicos; e o debate é político-partidário.

- Educação nos planos e propostas curriculares: elaborado por especialistas da área; está em sintonia com o "mundo da educação transformadora"; há densidade e continuidade em relação ao debate teórico e pedagógico; e o debate é teórico-metodológico.

Nos planos de governo há uma sobreposição da visão mercantilista/tecnicista. Nos planos de educação e nas propostas curriculares, há sobreposição da visão transformadora.

\section{CONSIDERAÇÕES FINAIS}

O movimento político pedagógico na educação brasileira, ao longo da história da República, apresenta continuidades e descontinuidades. Nas descontinuidades, assistimos a rupturas e recuos; nas continuidades, vivemos momentos de avanços e contradições. Todo o avanço na educação que iniciou nos anos 1930, fundado nos pressupostos da Escola Nova, seguiu pari passo por meio da implementação de políticas públicas que valorizavam a escola pública de boa qualidade, mas atendeu uma elite urbana e elegeu a escola como um forte instrumento na formação do sujeito trabalhador e obediente aos preceitos civis. O golpe civil-militar de 1964 interrompeu 


\section{Atos de Pesquisa em Educação - ISSN 1809-0354 \\ Blumenau, v.14, n.2, supl.1, p.718-744, out./nov. 2019 \\ DOI: http://dx.doi.org/10.7867/1809-0354.2019v14n2s1p718-744}

um longo processo de democratização da escola e de avanços nas políticas educacionais mais progressistas. Após quase vinte anos de retrocesso fundado no tecnicismo autoritário, a abertura política da primeira metade dos anos 1980 semeou esperança na sociedade brasileira, que almejava mais participação política nas várias esferas do Estado.

Neste estudo identificamos o processo de abertura política e o debate pela redemocratização da educação expressos em documentos oficiais do governo federal e de Santa Catarina. Em Santa Catarina, no período compreendido entre 1985 e 1991, podemos identificar a incorporação do espírito da redemocratização no Plano Estadual de Educação (III PEE 1985-1988), no plano de governo (Santa Catarina Rumo à Nova Sociedade 1987-1990), no plano da Secretaria de Educação (Plano de Ação 1988-1991) e na Proposta Curricular concluída em 1991. Porém, o III PEE e a Proposta Curricular é que sintetizaram o período analisado exprimindo a luta pela redemocratização (III PEE) e a necessidade de concretizar as ações para serem efetivadas junto à unidade escolar (Proposta Curricular).

Com relação aos PEEs, o primeiro havia sido aprovado em 1969 para um período de 10 anos (1970-1979), o segundo em 1980 para ser executado em quatro anos (1980-1983), e o terceiro abrangia o quadriênio 1985-1988. Houve diversas tentativas de elaborar um novo PEE, como a proposta de 1988-1991, que se convertesse no Plano de Ação da Secretaria de Estado da Educação. No governo Kleinübing (1991-1994), em 1994, foi apresentada outra proposta de PEE, que incorporava os discursos da "qualidade total na educação", porém não foi aprovada pelo CEE nem pela Assembleia Legislativa.

No segundo governo de Esperidião Amin (1999-2002) novamente foi formada uma equipe de trabalho para apresentar um novo PEE, que chegou até a ser enviado para o CEE e para a Assembleia, porém não foi aprovado. O governo Luiz Henrique da Silveira (2003-2010) desarquivou o PEE do governo anterior, fez uma nova leitura e apresentou outra versão, contudo não foi aprovado. Somente em 2015, no governo de Raimundo Colombo (2001-2018), obedecendo as diretrizes no II Plano Nacional de Educação, é que efetivamente foi aprovado o IV PEE para Santa Catarina (SANTA CATARINA, 2015). Portanto, foram 30 anos de espera para que a Secretaria de 
 \\ Blumenau, v.14, n.2, supl.1, p.718-744, out./nov. 2019 \\ DOI: http://dx.doi.org/10.7867/1809-0354.2019v14n2s1p718-744}

Estado da Educação tivesse outro Plano Estadual de Educação para orientar suas tomadas de decisão.

Com relação à Proposta Curricular, no governo Paulo Afonso (1995-1998) ela sofreu algumas alterações quando foram incorporados novos temas, sendo regida pela Lei de Diretrizes e Bases de 1996. Em 1998, foi apresentada outra redação, no entanto, ainda foram mantidos os fundamentos críticos que trouxeram para o debate os pressupostos da concepção histórico-cultural. (SANTA CATARINA, 1998).

Em 2005, foi apresentada mais uma Proposta Curricular, que era mais abrangente e adaptada às mudanças institucionais e regimentais que a educação brasileira tinha acumulado. Na apresentação da Proposta, novamente foi reafirmada a opção pela concepção histórico-cultural, que estava em execução desde 1991. (SANTA CATARINA, 2005). Já na última Proposta Curricular de 2014, percebe-se que há uma opção de não se fechar em torno de uma concepção teórica, mas de reconhecer os avanços obtidos com as propostas anteriores e apontar para a necessidade de seguir com a democratização da educação. (SANTA CATARINA, 2014).

Portanto, os efeitos positivos da redemocratização da educação iniciada em meados dos anos 1980 estenderam-se às duas décadas seguintes. Mesmo com os retrocessos da política econômica do neoliberalismo, a educação seguiu seu caminho transformador ao longo da década de 1990. O ambiente democrático garantiu a diversidade do debate e trouxe ganhos coletivos. O perigo é o revés fascista que cerceia os direitos e amordaça o debate. Por isso, é preciso escovar a história a contrapelo, inspirados em Walter Benjamin (1994), e buscar conhecer aqueles projetos que foram vencidos e que correm o risco de ser esquecidos.

\section{ALCIDES GOULARTI FILHO}

Professor da Universidade do Extremo Sul Catarinense - UNESC. Programa de Pósgraduação em Desenvolvimento Socioeconômico - PPGDS. Doutor em Economia pela UNICAMP.

\section{GIANI RABELO}




\section{Atos de Pesquisa em Educação - ISSN 1809-0354 \\ Blumenau, v.14, n.2, supl.1, p.718-744, out./nov. 2019 \\ DOI: http://dx.doi.org/10.7867/1809-0354.2019v14n2s1p718-744}

Professora da Universidade do Extremo Sul Catarinense - UNESC. Programa de Pósgraduação em Desenvolvimento Socioeconômico - PPGDS. Programa de Pósgraduação em Educação. Doutora em Educação pela UFRGS.

\section{REFERÊNCIAS}

AZEVEDO, Fernando et al. Manifesto dos Pioneiros da Educação Nova (1932) e dos educadores (1959). Recife: Fundação Joaquim Nabuco, Editora Massangana, 2010.

BENJAMIN, Walter. Magia e técnica, arte e política. São Paulo: Brasiliense, 1994.

BORMENY, Helena M. B. Bomeny. Três decretos e um ministério: a propósito da educação no Estado Novo. In: Repensando o Estado Novo. Organizadora: Dulce Pandolfi. Rio de Janeiro: Ed. Fundação Getulio Vargas, 1999.

BRASIL. Decreto no 19.402, de 14 de Novembro de 1930. Brasília: Câmara dos Deputados. Disponível em: <http://www2.camara.leg.br/atividade-

legislativa/legislacao >. Acesso em: ago. 2017.

BRASIL. Decreto no 19.850, de 11 de abril de 1930. Brasília: Câmara dos Deputados. Disponível em: <http://www2.camara.leg.br/atividadelegislativa/legislacao $>$. Acesso em: 14 ago.2017.

BRASIL. Plano Nacional de Educação. In: Revista Brasileira de Estudos Pedagógicos. Rio de Janeiro: Ministério da Educação e Saúde, v. XIII, n. 36, maioagosto/1949a.

BRASIL. Diretrizes e bases da educação nacional. In: Revista Brasileira de Estudos Pedagógicos. Rio de Janeiro: Ministério da Educação e Saúde, v. XIII, n. 36, maioagosto/1949b.

BRASIL. Lei no 4.024 de 20 de dezembro de 1961. Brasília: Câmara dos Deputados. Disponível em: <http://www2.camara.leg.br/atividade-legislativa/legislacao $>$. Acesso em: 10 ago. 2017.

BRASIL. Lei no 5.540 de 28 de novembro de 1968. Brasília: Câmara dos Deputados. Disponível em: <http://www2.camara.leg.br/atividade-legislativa/legislacao >. Acesso em: 05 ago. 2017.

BRASIL. Decreto-Lei no 464 de 11 de fevereiro de 1969. Brasília: Câmara dos Deputados. Disponível em: <http://www2.camara.leg.br/atividadelegislativa/legislacao >. Acesso em: 01 ago. 2017.

BRASIL. Lei Estadual no 4.394 de 20 de novembro de 1969. Florianópolis: Assembleia Legislativa do Estado de Santa Catarina. Disponível em: <http://200.192.66.20/alesc/PesquisaDocumentos.asp >. Acesso em: 11 ago. 2017. 
BRASIL. Lei no 5.692 de 11 de agosto de 1971. Brasília: Câmara dos Deputados. Disponível em: $<$ http://www2.camara.leg.br/atividade-legislativa/legislacao $>$. Acesso em: agosto de 2017.

BRASIL. Lei no 6.683 de 28 de agosto de 1979. Brasília: Câmara dos Deputados. Disponível em: <http://www2.camara.leg.br/atividade-legislativa/legislacao $>$. Acesso em: 15 ago. 2017.

BRASIL. Lei no 6.767 de 20 de dezembro de 1979. Brasília: Câmara dos Deputados. Disponível em: <http://www2.camara.leg.br/atividade-legislativa/legislacao >. Acesso em: 10 ago. 2017.

BRASIL. Decreto Estadual no 12.355 de 08 de outubro de 1980. Florianópolis: Assembleia Legislativa do Estado de Santa Catarina. Disponível em: <http://200.192.66.20/alesc/PesquisaDocumentos.asp >. Acesso em: 13 ago. 2017.

BRASIL. Lei no 7.486 de 06 de junho de 1986. Brasília: Câmara dos Deputados. Disponível em: <http://www2.camara.leg.br/atividade-legislativa/legislacao > Acesso em: 5 ago. 2017.

BRASIL. Lei no 9.394 de 20 de dezembro de 1996. Brasília: Câmara dos Deputados. Disponível em: <http://www2.camara.leg.br/atividade-legislativa/legislacao $>$. Acesso em: 11 ago. 2017.

BRASIL. III Plano Nacional de Desenvolvimento 1980-1985. Brasília: Secretaria de Planejamento, 1981.

BRASIL. III Plano Setorial de Educação, Cultura e Desportos. Brasília: Ministério da Educação e Cultura, 1982.

BRASIL. I Plano Nacional de Desenvolvimento da Nova República 1986-1989. Brasília: Presidência da República, 1986.

BRASIL. Política Nacional de Educação. Brasília: Ministério da Educação, 1989.

FÁVERI, M. Novembrada: as mulheres, o cárcere e as solidariedades. Fronteiras Revista Catarinense de História, v. 24, p. 61-86, 2014. Disponível em: $<$ http://www.anpuh-sc.org.br/revfront 24.htm>. Acesso em: 15 jan. 2018.

FERNANDES, Florestan. A Revolução burguesa no Brasil. Rio de Janeiro: Zahar Editores, 1981.

HENTZ, Paulo. Introdução. Proposta Curricular: Uma Contribuição para a Escola Pública do Pré-Escolar, 1ำGrau, 2ํㅡrau e Educação de Adultos. Florianópolis. Secretaria de Estado da Educação/ Coordenadoria de Ensino, 1991.

LAMPEDUSA, Giuseppe Tomasi di. O Leopardo. Editorial Teorema, 2007. 
Atos de Pesquisa em Educação - ISSN 1809-0354

Blumenau, v.14, n.2, supl.1, p.718-744, out./nov. 2019

DOI: http://dx.doi.org/10.7867/1809-0354.2019v14n2s1p718-744

RUMO À NOVA SOCIEDADE CATARINENSE: plano de governo março/87 a março/91. Florianópolis, 1987.

SANTA CATARINA. Plano Estadual de Educação 1970-1979. Florianópolis:

Secretaria da Educação e Cultura, 1969.

SANTA CATARINA. Plano Estadual de Educação 1980-1983. Florianópolis: Secretaria de Educação, 1980.

SANTA CATARINA. Carta aos catarinenses: prioridades aos pequenos. Florianópolis, 1982.

SANTA CATARINA. Plano Estadual de Educação 1985-1988: democratização da educação, a opção dos catarinenses. Florianópolis: Secretaria de Educação, 1985.

SANTA CATARINA. Plano Estadual de Educação 1988-1991. Florianópolis: Secretaria de Educação, 1988.

SANTA CATARINA. Plano Estadual de Educação. Florianópolis: Secretaria Estadual de Educação, Cultura e Desportos, 1994.

SANTA CATARINA. Plano Estadual de Educação 2001-2010. Florianópolis:

Secretaria de Educação e Desportos, 2002.

SANTA CATARINA. Plano Estadual de Educação: a sociedade construindo a educação dos catarinenses. Florianópolis: Secretaria da Educação e Inovação, 2004.

SANTA CATARINA. Plano Estadual de Educação 2015-2024. Florianópolis: Secretaria da Educação, 2015.

SANTA CATARINA. Plano de Ação da Secretaria de Estado da Educação 19881991. Florianópolis: Secretaria de Educação, 1988.

SANTA CATARINA. Proposta Curricular: uma contribuição para a escola pública do pré-escolar, $1^{\circ}$ grau, $2^{\circ}$ grau e educação de adultos. Florianópolis: Secretaria da Educação, 1991.

SANTA CATARINA. Proposta Curricular de Santa Catarina: educação infantil, ensino fundamental e médio. Florianópolis: COGEN, 1998.

SANTA CATARINA. Proposta Curricular de Santa Catarina: estudos temáticos.

Florianópolis: IOESC, 2005.

SANTA CATARINA. Proposta Curricular de Santa Catarina: formação integral na educação básica. Florianópolis: Secretaria da Educação, 2014. 
Blumenau, v.14, n.2, supl.1, p.718-744, out./nov. 2019

DOI: http://dx.doi.org/10.7867/1809-0354.2019v14n2s1p718-744

SANTA CATARINA. Lei Estadual no 16.794 de 14 de dezembro de 2015.

Florianópolis: Assembleia Legislativa do Estado de Santa Catarina. Disponível em: <http://200.192.66.20/alesc/PesquisaDocumentos.asp>. Acesso em: 12 ago. 2017.

VIDAL, Diana. 80 anos do Manifesto dos Pioneiros da Educação Nova: questões para debate. Educação e Pesquisa, São Paulo, v. 39, n. 3, p. 577-588, jun./set, 2013.

Esta obra está licenciada com uma Licença Creative Commons Atribuição 4.0 Internacional 